\title{
Effects of Diacetyl Flavoring Exposure in Mice Metabolism
}

\author{
Letícia Dias Lima Jedlicka $\left(\mathbb{D},{ }^{1,2}\right.$ Juciara da Costa Silva, ${ }^{3}$ Aleksandro Martins Balbino, ${ }^{1}$ \\ Giuseppe Bruno Neto, ${ }^{1}$ Danielle Zildeana Sousa Furtado, ${ }^{1}$ \\ Heron Dominguez Torres da Silva $\left(\mathbb{D},{ }^{1}\right.$ Fernanda de Barros Correia Cavalcanti $\left(\mathbb{D},{ }^{3}\right.$ \\ Karin Marie van der Heijden (iD, ${ }^{3}$ Carlos Alberto Avellaneda Penatti, ${ }^{3}$ \\ Etelvino José Henriques Bechara, ${ }^{4}$ and Nilson Antonio Assunção ${ }^{1}{ }^{1}$
}

\author{
${ }^{1}$ Instituto de Ciências Ambientais, Químicas e Farmacêuticas, Universidade Federal de São Paulo, Diadema, SP, Brazil \\ ${ }^{2}$ Instituto de Estudos em Saúde e Biológicas, Universidade Federal do Sul e Sudeste do Pará, Marabá, PA, Brazil \\ ${ }^{3}$ Universidade Nove de Julho, São Paulo, SP, Brazil \\ ${ }^{4}$ Instituto de Química, Universidade de São Paulo, SP, Brazil
}

Correspondence should be addressed to Nilson Antonio Assunção; nilson.assuncao@gmail.com

Received 26 January 2018; Revised 27 April 2018; Accepted 8 May 2018; Published 28 June 2018

Academic Editor: Gang Liu

Copyright (C) 2018 Letícia Dias Lima Jedlicka et al. This is an open access article distributed under the Creative Commons Attribution License, which permits unrestricted use, distribution, and reproduction in any medium, provided the original work is properly cited.

\begin{abstract}
Diacetyl is a flavoring that imparts a buttery flavor to foods, but the use or exposure to diacetyl has been related to some diseases. We investigated the effect of oral intake of diacetyl in male and female C57/Bl mice. We performed a target metabolomics assay using ultraperformance liquid chromatography paired with triple quadrupole mass spectrometry (UPLC-MS/MS) for the determination and quantification of plasmatic metabolites. We observed alterations in metabolites present in the urea and tricarboxylic acid (TCA) cycles. Peroxynitrite plasmatic levels were evaluated by a colorimetric method, final activity of superoxide dismutase (SOD) was evaluated by an enzymatic method, and mouse behavior was evaluated. Majority of the assay showed differences between control and treatment groups, as well as between genders. This may indicate the involvement of sex hormones in the regulation of a normal metabolic profile, and the implication of sex differences in metabolite disease response.
\end{abstract}

\section{Introduction}

It is increasingly common to use food additives to improve the appearance, quality, aroma, flavor, and longevity of food products [1]. Diacetyl is added to food products to improve taste by providing a butter-like flavor. Diacetyl $\left(\mathrm{C}_{4} \mathrm{H}_{6} \mathrm{O}_{2}\right.$, cas number: $431-03-8$ ) is a liquid at ambient temperature with a yellow or green-yellow color, and it is a diketone with a diffusive and pungent odor. Although diacetyl is directly added to human food and the compound is generally regarded as safe, other carbonyl compounds with low molecular weights can be toxic in large doses [2]. The acute oral $\mathrm{LD}_{50}$ (median lethal dose) of diacetyl for male and female rats is currently 3400 $\mathrm{mg} / \mathrm{kg}$ and $3000 \mathrm{mg} / \mathrm{kg}$, respectively, but the $\mathrm{LD}_{50}$ for mice has not yet been established [3]

Exposure to diacetyl has been extensively studied in recent years [4-11]. However, the majority of these studies focused on occupational exposure to diacetyl, mainly because of the occurrence of bronchiolitis obliterans in factory workers engaged in microwave popcorn production $[5,9]$.

We previously demonstrated the generation of acetyl radicals from the reaction between diacetyl and peroxynitrite [12-16] and also demonstrated the increase in protein acetylation in vivo after diacetyl consumption [17]. However, the broader effects of this flavoring compound have not been clearly studied. Even though foods with other chemical characteristics may result in highly reactive species once ingested, because diacetyl is an effective prooxidant, it will likely affect several metabolic routes $[18,19]$.

\section{Materials and Methods}

2.1. Experimental Protocol. Twelve-week-old male and female $\mathrm{C} 57 / \mathrm{Bl}$ mice were divided into four groups $(\mathrm{n}=6)$. The 
control groups did not receive any treatment, whereas treated groups received diacetyl in drinking water at concentrations of $300 \mathrm{mg} / \mathrm{kg} /$ day for 15 weeks. The mice were kept in a cabinet with $50-70 \%$ humidity at $19-23^{\circ} \mathrm{C}$. A $12 \mathrm{~h}$ light $/ 12 \mathrm{~h}$ dark cycle was used, and the mice were fed ad libitum. All procedures were approved by the UNIFESP Ethics Committee under number 975977013.

2.1.1. Dosage Selection. Based on previous studies in our laboratory [20] and the study conducted by Colley et al. [3], we chose a dosage of $300 \mathrm{mg} / \mathrm{kg} /$ day of diacetyl diluted in drinking water. Daily administration was chosen because diacetyl is a food flavoring widely used in the food industry, and it is considered safe by several agencies [21-24].

2.1.2. Determining Estrus Cycle Phase. The phase of the estrus cycle of the female mice was confirmed by vaginal smear. Before conducting the experiments and euthanasia in female mice, vaginal secretions were collected with a plastic pipette filled with $10 \mu \mathrm{L}$ of ultrapure water. The pipette tip was inserted into the mouse vagina to collect the secretion by aspiration. One drop of vaginal fluid was placed on a glass slide, dried at room temperature, and observed under a light microscope (Quimis, Brazil) with 10x and 40x objective lenses. Only female mice in the diestrus phase were used for the assay [25].

2.1.3. Sample Collection and Preparation. The mice were euthanized in a $\mathrm{CO}_{2}$ gas chamber (RED Industry and Commerce, Brazil) with a flow rate of $30 \%$ of the chamber volume per minute. Blood was collected by cardiac puncture with heparinized syringes, transferred to microtubes, and then centrifuged at $5000 \mathrm{rpm}$ for $1200 \mathrm{~s}$ at $4^{\circ} \mathrm{C}$. Plasma was collected and a protease inhibitor cocktail (Calbiochem, Germany) was added following the manufacturer's instructions. Plasma was frozen in liquid nitrogen and then stored at $-80^{\circ} \mathrm{C}$.

2.2. Metabolomics Assay. After pooling the plasma samples from each experimental and control group, we detected a total of 33 metabolites using an AbsoluteIDQ ${ }^{\mathrm{TM}}$ p180 kit (Biocrates Life Sciences AG, Austria), following manufacturer's instructions: L-alanine (Ala), L-arginine (Arg), Lasparagine (Asn), L-aspartate (Asp), L-citrulline (Cit), Lglutamine (Gln), L-glutamate (Glu), L-glycine (Gly), L-histidine (His), L-isoleucine (Ile), L-leucine (Leu), L-lysine (Lys), L-methionine (Met), L-ornithine (Orn), L-phenylalanine (Phe), L-asymmetric dimethylarginine (ADMA), Lcarnosine (Car), creatinine (Cre), L-DOPA (DOPA), Lhistamine (Hst), L-kynurenine (Kyn), L-methionine sulphoxide (Met-So), L-proline (Pro), L-putrescine (Put), L-sarcosine (Sar), serotonin (5-HT), L-trans-4-hydroxyproline (t4-OHPro), L-taurine (Tau), L-threonine (Thr), L-tryptophan (Trp), L-tyrosine (Tyr), L-valine (Val), and acetyl ornithine (AcOrn).

Table 1 contains the standard parameters used in the data acquisition of metabolomics analysis, as well as the coefficients of determination, equations, retention time $\left(t_{R}\right)$, mass spectrometry (MS), tandem mass spectrometry (MS/MS), detection limit (LD), quantification limit (LQ), linear range, cone volume (CV), collision energy (V), and internal standards (IS).

2.2.1. Statistical Analysis of Metabolomics Assay. Statistical analysis was conducted in two steps. Upon obtaining analyses of metabolites and performing the behavior screening, we used the software GraphPad Prism version 5.01 (San Diego, California, USA, https://www.graphpad.com/) to perform basic statistical comparisons of data with variance analysis through hypothesis testing ( $t$-test), analysis of variance (ANOVA), and the post hoc Bonferroni test. Secondly, exploratory data analysis (EDA) was used to identify systematic relations between variables when there were either nonexistent or incomplete expectations as to the nature of those relations by hierarchical cluster analysis (HCA), by clustering tree or dendrogram and principal component analysis (PCA), or by linear dimensionality reduction.

The statistical analysis was performed using the data analysis software system Statistica, version 10.0, by StatSoft Inc. (2011). The first step enabled us to verify differences between paired data groups not matched by specific tests and ANOVA. The second step allowed the ranking and clustering of data, followed by analysis according to group.

2.2.2. Enrichment Analysis of Metabolites. The enrichment analysis was performed using the global test package available at http://www.metaboanalyst.ca. It uses a generalized linear model to estimate a Q-statistic for each metabolite set, describing the correlation between compound concentration profiles and clinical outcomes.

2.3. SOD Assay. SOD was measured from plasma samples using the Superoxide Dismutase II Assay Kit (Cayman, USA). All reagents were used as supplied in the kit, prepared according to the manufacturer's instructions, and kept on ice during the assay. The absorbance was read at $450 \mathrm{~nm}$ using a plate reader. The SOD standard curve was plotted and linearized, and the SOD activity of the samples was calculated using the equation obtained from linear regression from the standards.

2.4. Peroxynitrite Assay. The serum peroxynitrite level was determined using the colorimetric method (Beckman et al., 1990). In brief, $10 \mu \mathrm{L}$ of serum was added to $90 \mu \mathrm{L}$ of cold $\mathrm{NaOH}\left(1.0 \mathrm{~mol} \mathrm{~L}^{-1}\right)$ and mixed well. $\mathrm{NaOH}\left(1.0 \mathrm{~mol} \mathrm{~L}^{-1}\right)$ was used as the blank. The blank absorbance was taken in a climatized quartz cuvette at $302 \mathrm{~nm}\left(10^{\circ} \mathrm{C}\right)$. A $10 \mu \mathrm{L}$ diluted sample was added to the cuvette and mixed three times. The absorbance at $302 \mathrm{~nm}$ of the diluted sample was recorded by a Spectramax spectrophotometer (Molecular Devices, USA).

2.5. Motor Locomotion and Behavior Testing. We investigated the chronic effect of diacetyl on animal motor locomotion and behavior. The open field test was chosen to determine the exploratory activity profile of the animal within the test arena, a divided area with central and peripheral (corner) limits. An animal spending time in the central area conveys low anxiety levels, whereas time spent in the corners conveys high anxiety 
TABLE 1: Coefficients of determination, equations, retention time $\left(t_{R}\right), M S, M S / M S, L D, ~ L Q$, linear range, CV, V, and IS.

\begin{tabular}{|c|c|c|c|c|c|c|c|c|c|c|c|}
\hline Metabolites & $\mathbf{R}^{2}$ & Equation & $\mathrm{t}_{\mathrm{R}} *$ & MS & MS/MS & $\mathrm{LD} * *$ & $\mathrm{LQ} * *$ & Linear range $* *$ & $\mathrm{CV}$ & $\mathrm{V}$ & IS \\
\hline 5-HT & 1 & $y=0.015 x-0.020$ & 1.27 & 241 & 60 & 0.42 & 1.40 & $5.00-400.00$ & 28 & 18 & Serotonin $\mathrm{D}_{4}$ \\
\hline Ala & 1 & $y=0.007 x-0.037$ & 1.62 & 225 & 44 & 0.05 & 0.18 & $20.00-600.00$ & 22 & 10 & Orn $\mathrm{D}_{6}$ \\
\hline Ac-orn & 0.99 & $y=30.165 x-10.120$ & 1.12 & 310 & 217 & 0.01 & 0.06 & $0.50-40.00$ & 32 & 24 & Orn $\mathrm{D}_{6}$ \\
\hline ADMA & 0.92 & $y=0.0168 x+-0.001$ & 1.29 & 338 & 46 & 0.07 & 0.20 & $0.25-20.00$ & 22 & 14 & Ala $\mathrm{D}_{4}$ \\
\hline Arg & 0.99 & $y=0.015 x+0.048$ & 1.12 & 310 & 217 & 0.03 & 0.10 & $5.00-400.00$ & 34 & 14 & $\operatorname{Arg}{ }^{15} \mathrm{~N}_{2}$ \\
\hline Asn & 1 & $y=0.0149 x+0.024$ & 1.18 & 268 & 87 & 0.01 & 0.05 & $5.00-400.00$ & 20 & 16 & Asn ${ }^{15} \mathrm{~N}_{2}$ \\
\hline Asp & 0.99 & $y=0.010 x-0.987$ & 1.41 & 269 & 116 & 0.01 & 0.03 & $5.00-400.00$ & 24 & 14 & Asp $D_{3}$ \\
\hline Car & 1 & $y=0.010 x+0.001$ & 1.00 & 362 & 136 & 0.08 & 0.26 & $0.50-40.00$ & 24 & 34 & His ${ }^{13} \mathrm{C}_{6}$ \\
\hline Cit & 1 & $y=0.021 x+0.007$ & 1.33 & 311 & 113 & 1.13 & 3.78 & $5.00-400.00$ & 22 & 24 & Cit ${ }^{13} \mathrm{CD}_{4}$ \\
\hline Cre & 0.99 & $y=0.008 x+0.041$ & 0.16 & 114 & 44 & 0.72 & 2.42 & $10.00-800.00$ & 32 & 14 & Creatinine $\mathrm{D}_{3}$ \\
\hline Dopa & 0.99 & $y=0.218 x-0.085$ & 1.33 & 333 & 198 & 0.16 & 0.55 & $0.50-40.00$ & 26 & 12 & Dopa $\mathrm{D}_{3}$ \\
\hline Gln & 1 & $y=0.019 x+0.006$ & 1.22 & 282 & 130 & 0.03 & 0.12 & $20.00-1600.00$ & 22 & 16 & $\mathrm{Gln} \mathrm{D}_{5}$ \\
\hline Glu & 0.99 & $y=0.012 x+0.030$ & 1.42 & 283 & 130 & 1.29 & 4.30 & $10.00-800.00$ & 26 & 16 & Glu $D_{3}$ \\
\hline Gly & 1 & $y=0.002 x+0.004$ & 1.29 & 211 & 76 & 0.10 & 0.35 & $25.00-2000.00$ & 22 & 10 & Gly ${ }^{13} \mathrm{C} 2{ }^{15} \mathrm{~N}$ \\
\hline His & 1 & $y=0.018 x+0.004$ & 1.00 & 291 & 110 & 0.76 & 2.55 & $5.00-400.00$ & 22 & 22 & His ${ }^{13} \mathrm{C}_{6}$ \\
\hline Hst & 0.97 & $y=0.110 x-0.078$ & 1.01 & 247 & 154 & 0.03 & 0.11 & $5.00-400.00$ & 22 & 12 & His ${ }^{13} \mathrm{C}_{6}$ \\
\hline Ile & 1 & $y=0.001 x-0.001$ & 2.51 & 267 & 69 & 0.15 & 0.52 & $5.00-400.00$ & 24 & 28 & Ile ${ }^{13} \mathrm{C}_{6}$ \\
\hline Kyn & 0.99 & $y=0.024 x+0.004$ & 2.43 & 344 & 146 & 0.08 & 0.27 & $1.00-80.00$ & 22 & 24 & Tyr $\mathrm{D}_{4}$ \\
\hline Leu & 0.99 & $\begin{aligned} \mathrm{y}= & 2.542 \mathrm{e}^{-005} \mathrm{x}+ \\
& 2.791 \mathrm{e}^{-006}\end{aligned}$ & 2.51 & 267 & 43 & 0.06 & 0.02 & $5.00-400.00$ & 24 & 38 & Ile ${ }^{13} \mathrm{C}_{6}$ \\
\hline Lys & 0.99 & $y=0.037 x-0.512$ & 2.50 & 417 & 324 & 0.07 & 0.26 & $10.00-800.00$ & 26 & 12 & Orn $\mathrm{D}_{6}$ \\
\hline Met & 1 & $y=0.017 x-0.002$ & 2.14 & 285 & 104 & 0.21 & 0.73 & $5.00-400.00$ & 22 & 18 & Met $D_{3}$ \\
\hline Met-So & 0.98 & $y=0.025 x+0.0435$ & 1.34 & 301 & 88 & 0.01 & 0.05 & $1.00-80.00$ & 18 & 30 & Met $\mathrm{D}_{3}$ \\
\hline Orn & 0.98 & $y=0.046 x-0.212$ & 2.38 & 403 & 310 & 0.002 & 0.01 & $5.00-400.00$ & 24 & 12 & Orn $\mathrm{D}_{6}$ \\
\hline Phe & 0.99 & $y=0.015 x+0.068$ & 2.56 & 301 & 120 & 0.006 & 0.02 & $5.00-400.00$ & 24 & 20 & Phe $\mathrm{D}_{5}$ \\
\hline Pro & 0.99 & $y=0.012 x+0.105$ & 1.61 & 251 & 70 & 0.04 & 0.14 & $5.00-400.00$ & 26 & 20 & Pro $D_{7}$ \\
\hline Put & 0.97 & $y=-0.033 x+0.270$ & 2.55 & 266 & 114 & 0,94 & 3.15 & $0.10-8.00$ & 26 & 12 & Putrescine $\mathrm{D}_{4}$ \\
\hline Sar & 1 & $y=2.68 x-0.157$ & 1.62 & 225 & 90 & 0.03 & 0.10 & $1.00-80.00$ & 20 & 10 & Sarcosine $\mathrm{D}_{3}$ \\
\hline T4-OH-Pro & 0.99 & $y=0.009 x-0.005$ & 1.29 & 267 & 132 & 0.01 & 0.06 & $1.00-80.00$ & 24 & 14 & Pro $\mathrm{D}_{7}$ \\
\hline Tau & 0.91 & $y=0.016 x+0.035$ & 1.00 & 261 & 126 & 0.03 & 0.10 & $2.50-200.00$ & 30 & 14 & Taurine ${ }^{13} \mathrm{C}_{2}$ \\
\hline Thr & 1 & $y=0.020 x+0.020$ & 1.53 & 255 & 73 & 0.07 & 0.26 & $5.00-400.00$ & 22 & 18 & Thr ${ }^{13} \mathrm{C} 4{ }^{15} \mathrm{~N}$ \\
\hline $\operatorname{Trp}$ & 1 & $y=0.015 x-0.015798$ & 2.48 & 317 & 136 & 0.01 & 0.05 & $5.00-400.00$ & 26 & 16 & $\operatorname{Trp}{ }^{15} \mathrm{~N}_{2}$ \\
\hline Tyr & 1 & $\begin{aligned} y= & 0.0258201 x \\
& +0.0219755\end{aligned}$ & 1.94 & 340 & 188 & 0.003 & 0.01 & $5.00-400.00$ & 26 & 22 & Tyr $\mathrm{D}_{4}$ \\
\hline Val & 0.99 & $y=0.013 x+0.021$ & 2.21 & 2534 & 72 & 0.01 & 0.06 & $10.00-800.00$ & 24 & 16 & Val $D_{8}$ \\
\hline
\end{tabular}

$* \min , * *\left(\mu \mathrm{mol} \mathrm{L}^{-1}\right)$

levels [26]. The open field test arena consisted of an open square box with $50 \mathrm{~cm}$ sides, with a black square central area with $25 \mathrm{~cm}$ sides.

Upon 15 weeks of exposure to oral diacetyl, male and female mice were tested in the open field arena for a $300 \mathrm{~s}$ session. Behavior was analyzed and scored according to the total time spent locally, within either central or peripheral zones. In addition, we tabulated parameters of animal selfcare and well-being (e.g., grooming, crossing, and standing up) as measures of normal social behavior. All behavioral tests were recorded with a Sony 12.1 camera and quantified using OPEN FLD software (Stefano Pupe, Brazil), which follows animal movement within the arena.

\section{Results and Discussion}

3.1. Metabolomic Differences in Male and Female Mice Treated Orally with $300 \mathrm{mg} / \mathrm{kg} /$ day of Diacetyl over 15 Weeks. Diacetyl is used as a food additive, but exposure and ingestion of this compound may lead to an imbalance in the body and the development of diseases $[27,28]$ which can alter the production of metabolic pathway intermediates. Thus, metabolites may reflect the conditions of the processes underlying cellular homeostasis, reflecting the relationships between cellular processes and biochemical pathways [28, 29]. The body tends to respond to these changes with intracellular and extracellular adjustments to maintain homeostasis [30,31]. 
TABLE 2: Plasma metabolite concentrations from female and male groups treated with $300 \mathrm{mg} / \mathrm{kg} /$ day of diacetyl for 15 weeks.

\begin{tabular}{|c|c|c|c|c|}
\hline Metabolite & Control Female* & $300 \mathrm{mg} / \mathrm{kg} /$ day Female $* *$ & Control Male $*$ & $300 \mathrm{mg} / \mathrm{kg} /$ day Male $* *$ \\
\hline 5-HT & $0.87 \pm 0.03$ & $1.33 \pm 0.03(\uparrow)$ & $1.27 \pm 0.03$ & $6.83 \pm 0.03(\uparrow)$ \\
\hline Ac-Orn & $4.37 \pm 0.70$ & $11.00 \pm 3.10(\uparrow)$ & $2.97 \pm 0.03$ & $4.13 \pm 0.03(\longleftrightarrow)$ \\
\hline ADMA & $63.00 \pm 2.00$ & $104.00 \pm 2.35(\uparrow)$ & $0.6 \pm 0.11$ & $0.57 \pm 0.03(\longleftrightarrow)$ \\
\hline ALA & $215.00 \pm 4.23$ & $706.00 \pm 5.78(\uparrow)$ & $240.15 \pm 4.20$ & $421,00 \pm 3.72(\uparrow)$ \\
\hline Arg & $70.00 \pm 1.47$ & $122.00 \pm 1.54(\uparrow)$ & $75.00 \pm 1.86$ & $114.00 \pm 3.47(\uparrow)$ \\
\hline Asn & $110.00 \pm 4.25$ & $449.0 \pm 12.08(\uparrow)$ & $30 \pm 0.81$ & $65.0 \pm 1.46(\uparrow)$ \\
\hline Asp & $197.00 \pm 13.90$ & $97.00 \pm 12.77(\downarrow)$ & $16.00 \pm 1.90$ & $18.00 \pm 2.70(\longleftrightarrow)$ \\
\hline Car & $51.00 \pm 0.73$ & $146.00 \pm 3.02(\uparrow)$ & $0.97 \pm 0.03$ & $0.70 \pm 0.06(\uparrow)$ \\
\hline Cit & $6.83 \pm 0.68$ & $26.00 \pm 0.63(\uparrow)$ & $40.00 \pm 0.94$ & $66.00 \pm 0.70(\uparrow)$ \\
\hline Cre & $8667.00 \pm 654.00$ & $8642.00 \pm 7370.00(\longleftrightarrow)$ & $19.00 \pm 1.01$ & $8.20 \pm 11.00(\downarrow)$ \\
\hline Dopa & $0.87 \pm 0.03$ & $0.93 \pm 0.03(\longleftrightarrow)$ & $0.70 \pm 0.00$ & $0.43 \pm 0.30(\downarrow)$ \\
\hline Gln & $239.00 \pm 6.56$ & $1898.00 \pm 61.40(\uparrow)$ & $485.00 \pm 15.40$ & $760.00 \pm 15.10(\uparrow)$ \\
\hline Glu & $136.00 \pm 8.50$ & $111.00 \pm 5.40(\downarrow)$ & $62.00 \pm 3.44$ & $93.00 \pm 10.50(\uparrow)$ \\
\hline Gly & $439.00 \pm 15.60$ & $1988.00 \pm 11.00(\uparrow)$ & $56.00 \pm 4.07$ & $82.00 \pm 3.09(\uparrow)$ \\
\hline His & $439.00 \pm 2.96$ & $1988.00 \pm 27.40(\uparrow)$ & $56.00 \pm 0.20$ & $82.00 \pm 1.31(\uparrow)$ \\
\hline Hst & $0.30 \pm 0.00$ & $0.50 \pm 0.00(\uparrow)$ & $1.43 \pm 0.03$ & $0.97 \pm 0.03(\downarrow)$ \\
\hline Ile & $19.00 \pm 0.20$ & $36.00 \pm 1.15(\uparrow)$ & $66.00 \pm 0.79$ & $114.00 \pm 0.55(\uparrow)$ \\
\hline Kyn & $22.00 \pm 0.30$ & $27.00 \pm 0.52(\uparrow)$ & $2.07 .0 \pm 0.10$ & $0.8 \pm 0.00(\downarrow)$ \\
\hline Leu & $33.00 \pm 9.87$ & $63.00 \pm 11.70(\uparrow)$ & $113.0 \pm 9.17$ & $213.00 \pm 4.50(\uparrow)$ \\
\hline Lys & $73.00 \pm 3.69$ & $106.00 \pm 38.00(\uparrow)$ & $182.00 \pm 4.05$ & $348.0 \pm 1.07(\uparrow)$ \\
\hline Met & $6.80 \pm 0.06$ & $18.00 \pm 0.55(\uparrow)$ & $33.00 \pm 0.72$ & $50.00 \pm 0.35(\uparrow)$ \\
\hline Met-SO & $0.80 \pm 0.26$ & $26.00 \pm 0.20(\uparrow)$ & $2.57 \pm 0.24$ & $2.77 \pm 0.12(\longleftrightarrow)$ \\
\hline Orn & $17.00 \pm 1.74$ & $11.00 \pm 2.33(\downarrow)$ & $60.0 \pm 0.17$ & $120.00 \pm 0.68(\uparrow)$ \\
\hline Phe & $118.00 \pm 1.23$ & $203.00 \pm 2.59(\uparrow)$ & $71.00 \pm 0.95$ & $93.00 \pm 0.19(\uparrow)$ \\
\hline Pro & $12.00 \pm 0.22$ & $46.00 \pm 0.72(\uparrow)$ & $69.00 \pm 0.26$ & $108.00 \pm 2.13(\uparrow)$ \\
\hline Put & $6.07 \pm 0.52$ & $7.05 \pm 0.37(\longleftrightarrow)$ & $0.73 \pm 0.07$ & $1.13 \pm 0.03(\downarrow)$ \\
\hline Sar & $12.00 \pm 0.48$ & $41.00 \pm 2.29(\uparrow)$ & $14.00 \pm 0.76$ & $26.00 \pm 0.96(\uparrow)$ \\
\hline T4-OH-Pro & $14.00 \pm 1.41$ & $1.87 \pm 0.22(\downarrow)$ & $0.87 \pm 0.07$ & $0.5 \pm 0.32(\longleftrightarrow)$ \\
\hline Tau & $58.00 \pm 4.33$ & $186.00 \pm 3.50(\uparrow)$ & $208.00 \pm 1.70$ & $329.00 \pm 2.89(\uparrow)$ \\
\hline Thr & $75.00 \pm 0.92$ & $382.00 \pm 0.41(\uparrow)$ & $101.00 \pm 2.14$ & $138.00 \pm 2.89(\uparrow)$ \\
\hline $\operatorname{Trp}$ & $69.00 \pm 0.43$ & $192.00 \pm 0.58(\uparrow)$ & $90.00 \pm 0.20$ & $81.00 \pm 0.58(\downarrow)$ \\
\hline Tyr & $148.00 \pm 3.04$ & $297.00 \pm 0.21(\uparrow)$ & $69.00 \pm 1.79$ & $96.0 \pm 1.41(\uparrow)$ \\
\hline Val & $47.00 \pm 0.22$ & $99.00 \pm 1.35(\uparrow)$ & $155.00 \pm 2.44$ & $240.00 \pm 2.90(\uparrow)$ \\
\hline
\end{tabular}

$\uparrow$ significant increase in concentration compared to respective control group; $\downarrow$ significant decrease in concentration compared to respective control group; $\longleftrightarrow$ concentration does not have significant difference from control group.

Sexual dimorphism is present in several species, in which nonsexual characteristics are present differently between the sexes. These differences encompass metabolites, lipid-derived molecules, cell regulatory processes, reactions to drugs [32], reactive oxygen species (ROS) signaling, and stress response [33]. The differing levels of hormones like progesterone, estrogen, and testosterone between the sexes are responsible for most of these differences. However, the differences go beyond the physical characteristics and may influence the functioning of the organism and may lead to differences in the metabolic profile $[34,35]$.

Because males and females may have different responses to a given treatment and/or susceptibility to disease, it is important to individually analyze the male and female results [19]. The metabolic analyses proceeded with male and female control groups in addition to groups treated with 300 $\mathrm{mg} / \mathrm{kg} /$ day. Results were compared between the male and female controls in order to look for sex-dependent differences prior the analysis of the diacetyl treatment. We observed sexspecific differences in metabolite concentrations (Table 2).

We also observed differences in metabolite levels between sexes after diacetyl treatment (Figure 1(a)), which can be attributed to sexual dimorphism. The metabolites 5-HT, Ala, Arg, Asn, Cit, Gln, Gly, His, Ile, Leu, Met, Phe, Pro, Sar, Tau, Thr, Tyr, and Val increased in both male and female treated groups compared with the respective controls (Figure 1(b)). The metabolites Ac-Orn, ADMA, Car, Hist, Kyn, Met-So, and Trp increased in only the female treated group compared with its control group, whereas metabolites Glu, Put, and Orn increased in only the male treated groups compared to control. All these increased metabolites are involved in lipid and amino acid metabolism and genetic information 


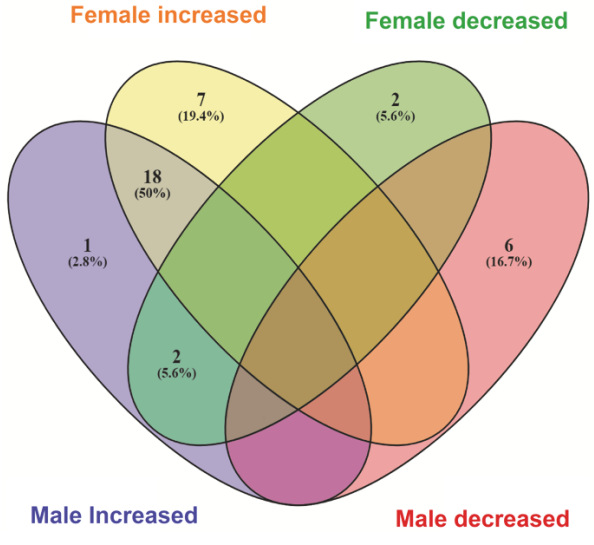

(a)

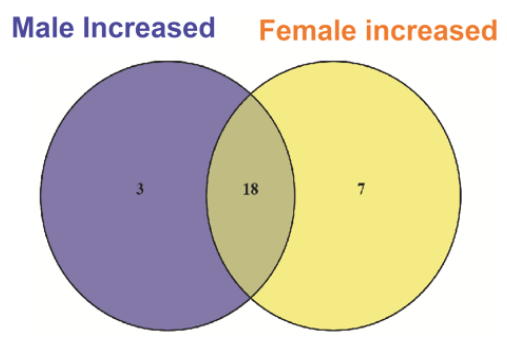

(b)

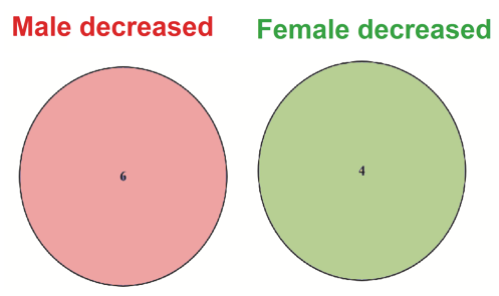

(c)

FIGURE 1: Changes in metabolic profile from male and female control groups and groups treated with $300 \mathrm{mg} / \mathrm{kg} /$ day of diacetyl. (a) Venn diagram of number of metabolites that increased and decreased in groups treated with diacetyl. (b) Venn diagram of number of metabolites that increased in groups treated with diacetyl. (c) Venn diagram of number of metabolites that decreased in groups treated with diacetyl.

processing pathways $[36,37]$. All cellular functions depend on metabolism [38].

Different metabolites decreased in both groups treated with diacetyl in comparison with the respective control groups (Figure 1(c)). The metabolites Asp, T4-OH-Pro, Orn, and Glu showed decreased levels in the female treated group compared with the female control group; the metabolites Dopa, Car, Cre, Kyn, Trp, and Hst showed decreased levels in the male treated group. The other metabolites did not show a statistical difference compared with their respective controls.

The plasma metabolites show different intensities in all groups (Figure 2). The metabolites with the highest values are in red, while the lowest appear in yellow and green, making it possible to visualize the difference of the metabolic profile among the groups with more clarity. The heatmap shows that diacetyl alters metabolism in both male and female groups. This data provides new insights into sex-specific responses to diacetyl treatment, as well as metabolism differences [39].

The difference between male and female metabolic profiles after diacetyl treatment was associated with gender. The differences between the metabolic profiles of male and female groups is evident, but the response to diacetyl exposure was observed independently of sex. We performed multivariate analyses for all groups that included all analyzed metabolites (Figure 3). PCA analysis allowed us to identify differences or similarities between all groups. We observed an efficient separation between the male and female groups (Figure 3(a)). A subdivision separating the diacetyl-treated groups can also be seen, where control groups are in the upper quadrants and treated groups are in the lower quadrants.

The dendrogram provides more evidence for the separation of the four groups (Figure 3(b)). The $y$-axis represents the experimental groups in descending order of similarity, and the position of the line on the $x$-axis indicates the distances between the groups. The female groups have the greatest similarity because they have the shortest distance between them (Figure 3(b)). The female groups formed the first branch; the male groups formed the second branch. The

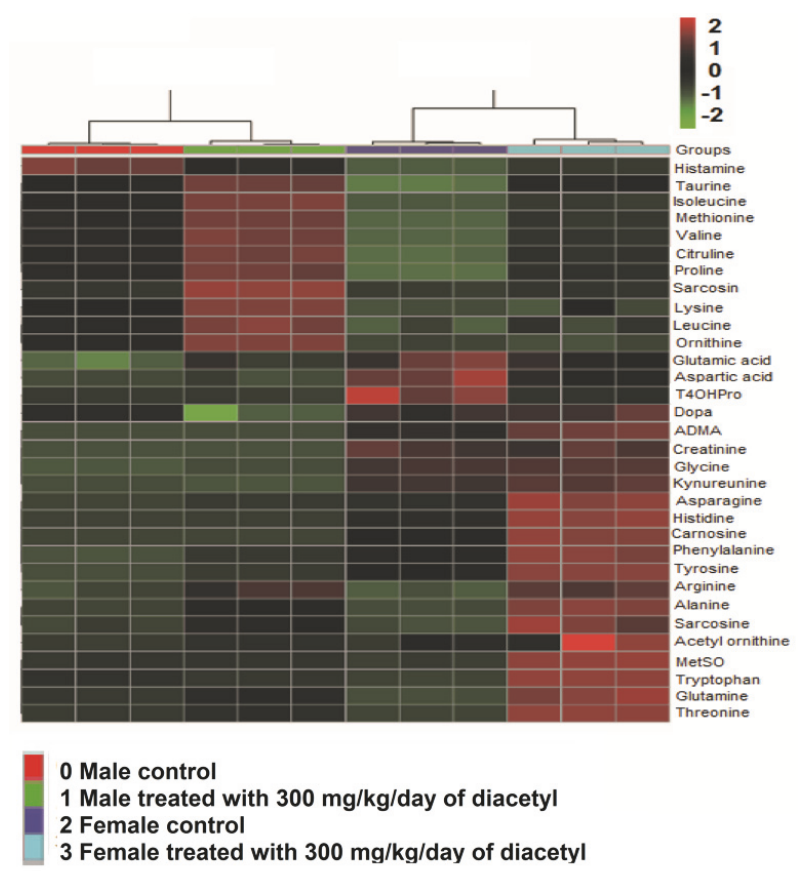

FIGURE 2: Heatmap of plasma metabolites from male controls, males treated with $300 \mathrm{mg} / \mathrm{kg} /$ day of diacetyl, female controls, and females treated with $300 \mathrm{mg} / \mathrm{kg} /$ day of diacetyl.

male and female branches remained distinct because of the differences between their respective metabolic profiles.

The first branch has two subbranches that distinguish female controls from females treated with $300 \mathrm{mg} / \mathrm{kg} /$ day of diacetyl. The second branch also contained two subbranches that distinguished male controls from treated males. These results show both the dissimilarity between sexes and the difference in treatment with $300 \mathrm{mg} / \mathrm{kg} /$ day of diacetyl. This difference in metabolic profile found between male and female groups may be related to natural sexual dimorphism. 


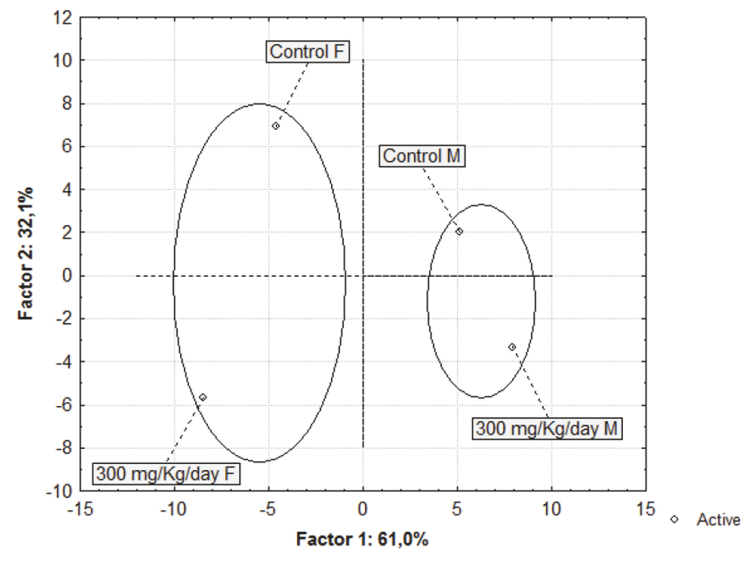

(a)

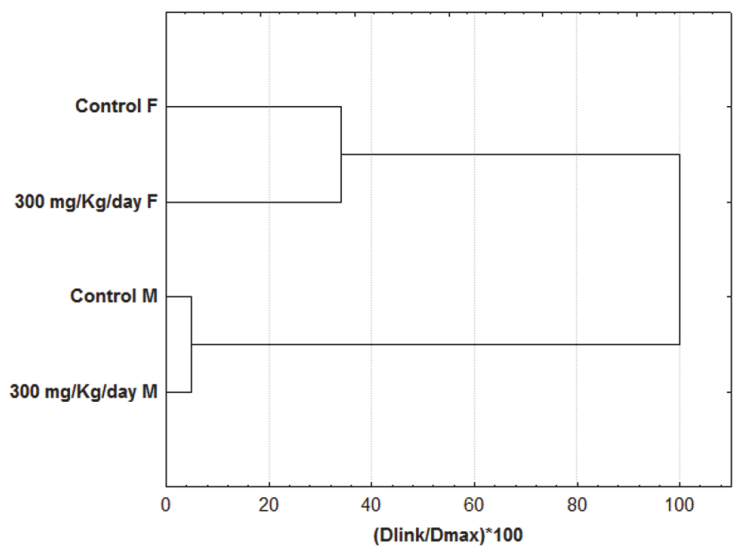

(b)

FIGURE 3: Multivariate analysis: principal component analysis (PCA) and dendrogram of male and female mice in control groups and groups treated with $300 \mathrm{mg} / \mathrm{kg} /$ day of diacetyl. (a) PCA of male and female mice in control groups and groups treated with $300 \mathrm{mg} / \mathrm{kg} / \mathrm{day}$ of diacetyl. (b) Dendrogram showing Euclidean distance-based similarity of metabolite levels in control and treated groups.

Sex hormones also contribute to the differences between sexes and are associated with incidence and progression of some diseases [20-22]. For example, estrogens are atheroprotective and vasoprotective and may exert potent antioxidant actions [21]. Estrogen has an antiapoptotic effect in muscle and neural tissues upon stress. Testosterone also shows antiapoptotic activity in muscle cell lines upon oxidative stress, but testosterone in rat myocytes showed a proapoptotic effect [38]. Metabolic profile differences between male and female control groups are likely attributable to the effects of estrogen.

\subsection{Possible Pathways and Diseases Altered in Males and} Females from Groups Treated with $300 \mathrm{mg} / \mathrm{kg} /$ day of Diacetyl. When an organism's homeostasis is disrupted, this may lead to some dysfunction that impacts metabolism or promotes disease. The organism can also develop a stress response to help to maintain homeostasis $[39,40]$. Diacetyl and other $\alpha$ dicarbonyl compounds promote chemical disorders including mutagenesis, cancer, aging, diabetes, neurodegenerative processes, several metabolism errors, and inflammatory diseases [13].

To relate the diacetyl intake status with the plasma metabolite expression data, we performed the metabolite set enrichment analysis with a database (http://metaboanalyst.ca). The metabolites were ranked according to the increases or decreases in groups treated with $300 \mathrm{mg} / \mathrm{kg} /$ day of diacetyl when compared with the respective controls. This analysis showed metabolic pathways that were altered after diacetyl treatment in male and female groups.

The metabolic profile reflects the physiological, developmental, and pathological processes of the organism, which can inform disease prognosis [41]. In this way, metabolomic analysis can be a valuable tool to analyze pathway alterations, which helps understand biochemical disease mechanisms and the effects of drugs and potentially toxic substances [42].

The increased metabolites observed in male and female groups treated with $300 \mathrm{mg} / \mathrm{kg} /$ day of diacetyl may be

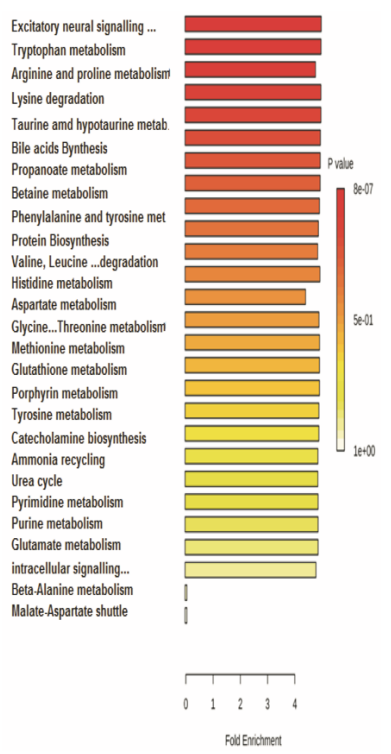

(a)

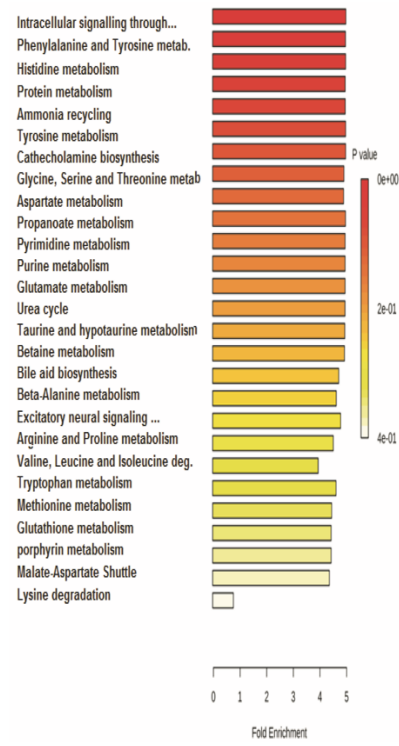

(b)
FIGURE 4: Quantitative set enrichment analysis of metabolites in male and female groups treated with $300 \mathrm{mg} / \mathrm{kg} /$ day of diacetyl. (a) Affected pathways in males. (b) Affected pathways in females.

involved in some major pathways (Figures 4(a) and 4(b)). The metabolite set enrichment analysis confirmed involvement of diacetyl treatment in some pathways. The table data set generated by quantitative analysis using the MetaboAnalyst tools is available in the supplementary material (SM1 and SM2). The same pathways were affected in males and females treated with diacetyl, but each group responded somewhat differently. The treated males had a greater change in excitatory neural signaling through $5-\mathrm{HT}$, whereas the treated females showed a greater change in intracellular signaling through histamine $\mathrm{H} 2$ receptor and histamine. 


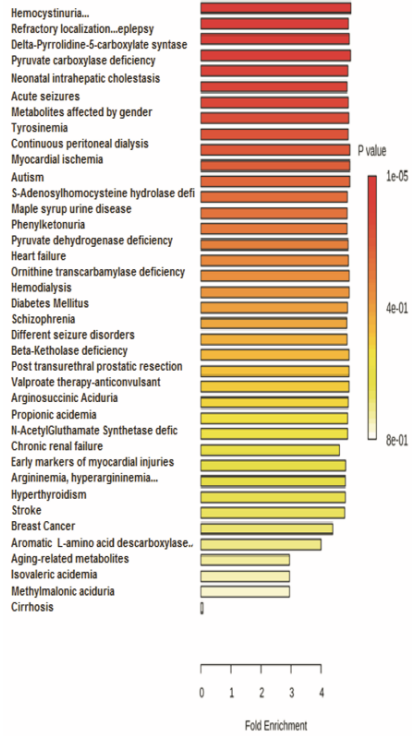

(a)

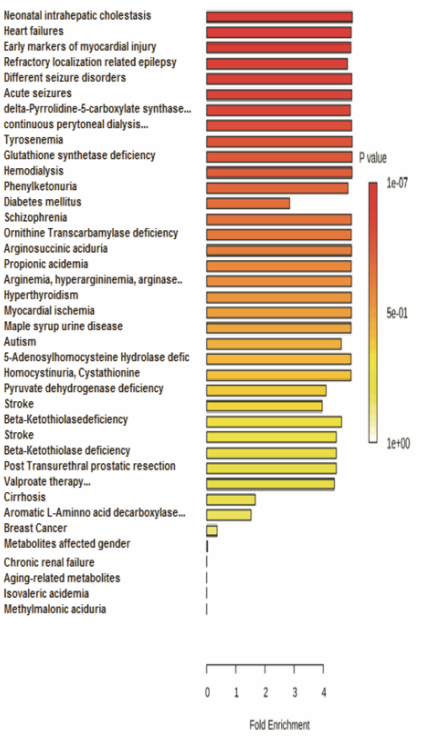

(b)

Figure 5: Quantitative set enrichment analysis of metabolites in male and female groups treated with $300 \mathrm{mg} / \mathrm{kg} / \mathrm{day}$ of diacetyl. (a) Related diseases for male treated group. (b) Related diseases for female treated group.

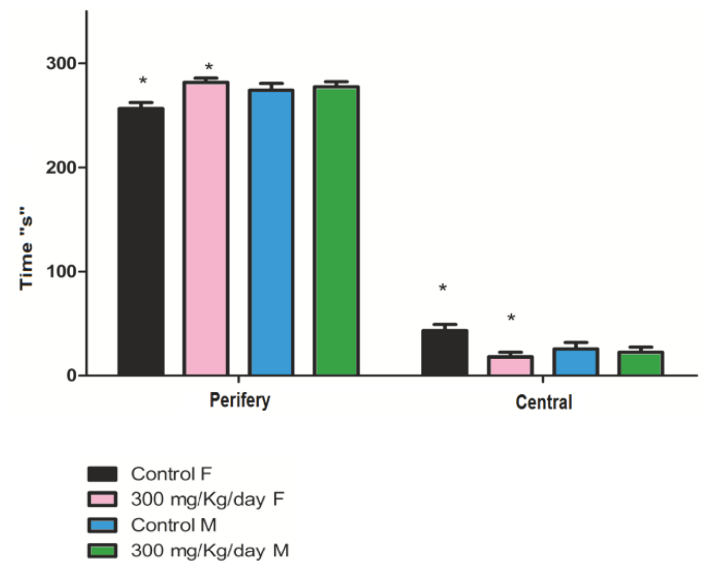

(a)

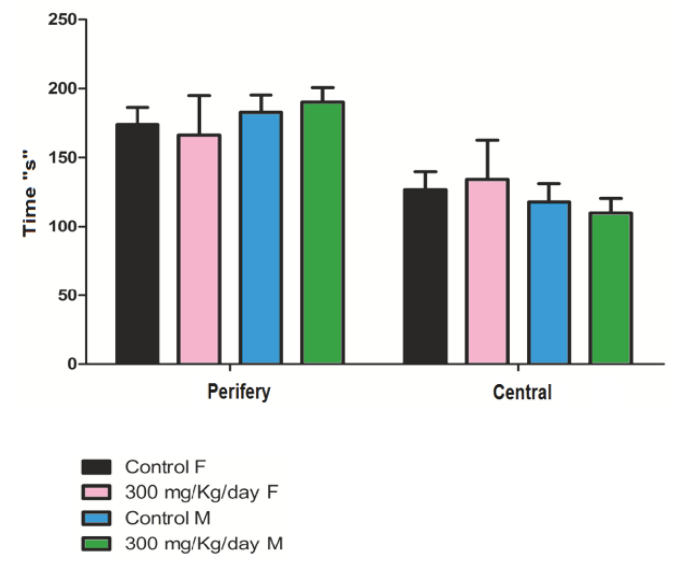

(b)

FIGURE 6: Open field test results, with time (s) spent in periphery and central regions. (a) First round of analysis. (b) Second round of analysis.

Some diseases affect the metabolic profile, so a precise metabolite quantification assists in proper diagnosis [40]. Metabolites were ranked according to their increases or decreases in groups treated with $300 \mathrm{mg} / \mathrm{kg} /$ day of diacetyl compared with the respective control group (SM 3, SM 4). Metabolite expression is correlated with the likelihood of certain diseases (Figures 5(a) and 5(b)). We included diseases if at least five of the investigated metabolites involved in their pathological mechanisms were altered after diacetyl treatment. The same diseases affected both male and female groups, but the most relevant male disease was homocystinuria and the most relevant female disease was intrahepatic cholestasis (Figures 5(a) and 5(b)).
3.3. Behavior Screening in Female and Male Mice after LongTerm Exposure to Diacetyl. Behavior screening was performed to investigate the effects of diacetyl intake on mice behavior. We observed a discrete difference between male and female control groups, as well as between the female control group and the female group treated with diacetyl (Figure 6(a)). These differences can be associated with differing endocrine regulation due to sexual dimorphism [43-49]. A second round of open field experiments with other groups of animals that received the same diacetyl dose confirmed the same altered behavior (Figure 6(b)).

Other parameters were also observed in the open field test, including grooming, stand-up events, and crossing 
TABLE 3: Open field test in male and female control groups and groups treated with $300 \mathrm{mg} / \mathrm{kg} / \mathrm{day}$ of diacetyl.

\begin{tabular}{lcccc}
\hline Group & Round of analysis & Crossing events & Stand-up events & Grooming events \\
\hline Females, control & 1 & $33.60 \pm 1.47$ & $37.40 \pm 2.94$ & $2.40 \pm 2.07$ \\
Females, 300 mg/kg/day diacetyl treatment & 1 & $23.20 \pm 5.59$ & $29.20 \pm 2.37$ & $3.60 \pm 1.89$ \\
Males, control & 1 & $24.33 \pm 1.92$ & $28.33 \pm 1.93$ & $1.50 \pm 0.50$ \\
Males, 300 mg/kg/day diacetyl treatment & 1 & $24.33 \pm 3.56$ & $21.50 \pm 1.52$ & $3.17 \pm 0.95$ \\
Females, control & 2 & $40.00 \pm 6.85$ & $31.00 \pm 9.14$ & $2.00 \pm 0.45$ \\
Females, 300 mg/kg/day diacetyl treatment & 2 & $39.60 \pm 7.52$ & $31.60 \pm 6.87$ & $3.80 \pm 0.92$ \\
Males, control & 2 & $37.60 \pm 3.34$ & $20.40 \pm 5.77$ & $2.60 \pm 0.93$ \\
Males, 300 mg/kg/day diacetyl treatment & 2 & $42.00 \pm 2.59$ & $19.40 \pm 2.01$ & $2.40 \pm 0.25$ \\
\hline
\end{tabular}

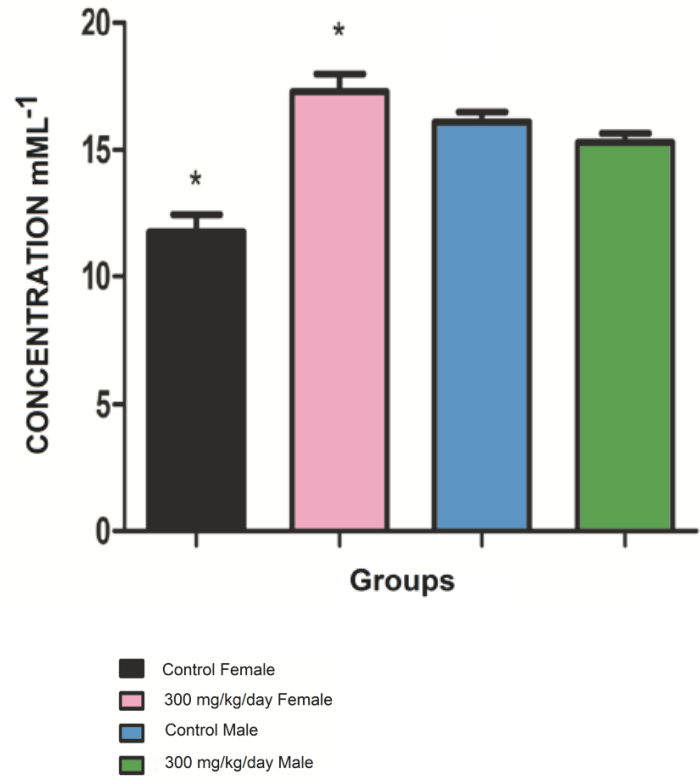

(a)
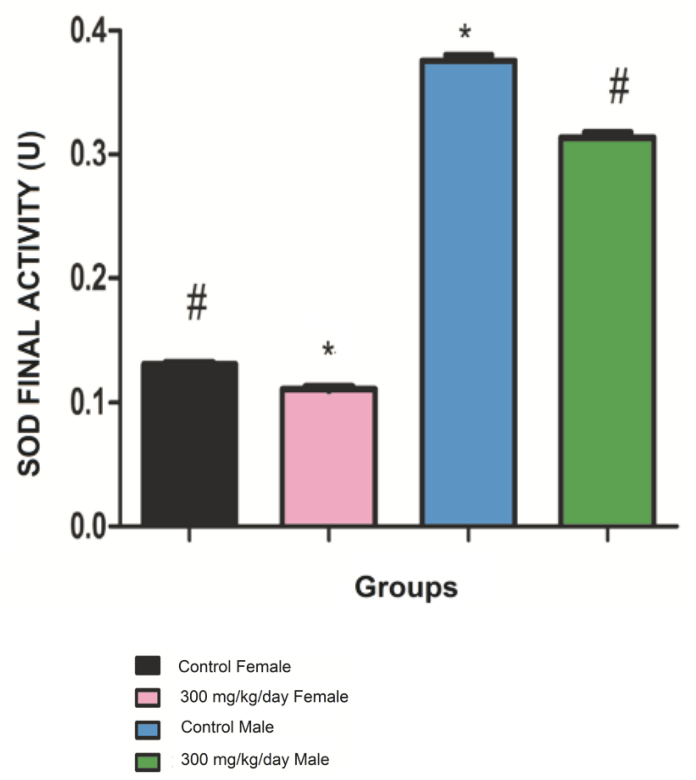

(b)

FIGURE 7: Peroxynitrite levels and SOD final activity in male and female control groups and groups treated with $300 \mathrm{mg} / \mathrm{kg} / \mathrm{day}$ of diacetyl. (a) Peroxynitrite levels in male and female control groups and groups treated with $300 \mathrm{mg} / \mathrm{kg} /$ day of diacetyl. (b) SOD final activity in male and female control groups and groups treated with $300 \mathrm{mg} / \mathrm{kg} /$ day of diacetyl. * groups with statistical difference (ANOVA and Posttest Bonferroni) from female control group ( $\mathrm{p}<0.0001)$. Values expressed as mean \pm SEM. \# groups with statistical difference (ANOVA and Posttest Bonferroni) from male control groups $(\mathrm{p}<0.0001)$. Values expressed as mean $\pm \mathrm{SEM}$.

frequency between the periphery and central regions (Table 3). However, we did not observe changes in the first or second rounds of analysis.

3.4. SOD and Peroxynitrite Assay. Peroxynitrite and other reactive nitrogen species help regulate some physiological functions. However, the generation of peroxynitrite can happen in inflammation and antioxidant system failures [29].

We observed different responses to diacetyl between males and females regarding peroxynitrite levels in $\mathrm{mML}^{-1}$ (Figure 7(a)) and SOD final activity (Figure 7(b)). Peroxynitrite levels were higher in treated females $(17.25 \pm 0.71)$ than in control females $(11.76 \pm 0.68)$ (Figure $7(\mathrm{a})$ ). Peroxynitrite levels were similar between the control males $(16.08 \pm 0.39)$ and the treated males $(15.29 \pm 0.34)$ (Figure $7(\mathrm{a})$ ). These results demonstrate that female groups produced more peroxynitrite when exposed to $300 \mathrm{mg} / \mathrm{kg} /$ day of diacetyl, while male groups did not exhibit the same increase. Peroxynitrite is a prooxidant substance and is involved in oxidative stress $[28,50,51]$. These data suggest there is a sex-related difference in response during oxidative stress. Testosterone stimulates the formation of peroxynitrite and peroxynitrite precursors such as superoxide, nitric oxide, and xanthine oxidase [34], whereas estradiol is associated with decreased peroxynitrite levels [52]. The differing responses to diacetyl exposure may be because sex hormones naturally induce higher baseline peroxynitrite levels in male controls than in female controls.

Superoxide dismutase (SOD) is an antioxidant enzyme that defends the body against oxidative stress [52]. SOD final activity (U) decreased in treated male and female groups $(0.313 \pm 0.004$ and $0.111 \pm 0.001$, respectively $)$ when compared to the male and female control groups $(0.375 \pm 0.004$ and $0.130 \pm 0.001$, respectively) (Figure $7(\mathrm{~b})$ ). This suggests diacetyl decreases SOD activity. 
Diacetyl treatment increased plasma peroxynitrite levels and decreased SOD final activity in female groups when compared to control. SOD final activity also decreased in the male treated group when compared to control, but peroxynitrite levels did not change. Both female and male groups treated with diacetyl demonstrated the imbalance between the prooxidants and antioxidants, suggesting that diacetyl intake is negatively correlated with oxidative stress.

\section{Conclusion}

Metabolomics of male and female C57/black mice showed different biochemical patterns. Diacetyl administered orally to male and female mice promoted metabolomic changes in a sex-dependent manner. This suggests the involvement of sex hormones in the regulation of a normal metabolic profile, and the implication of sex-based differences in metabolite disease response.

The metabolite levels of 5-HT, Ala, Arg, Asn, Cit, Gln, Gly, His, Ile, Leu, Met, Phe, Pro, Sar, Tau, Thr, Tyr, and Val were increased in male and female treated groups. Some metabolites increased only in the female treated group compared to control (Ac-Orn, ADMA, Hst, Kyn, Met-SO, and Trp), and some metabolites increased only in the male treated group compared to control (Glu, Orn, and Put). The metabolite levels of Asp, Glu, Orn, and T4-OH-Pro decreased in the female treated group compared to control; the metabolite levels of Cre, Dopa, Hst, Kyn, Car, and Trp decreased in the male treated group compared to control.

The current work confirms the studies that demonstrated the diacetyl can modify peptides and proteins by acetylation $[8,10]$, and various metabolic routes involve acetylation, including the urea cycle [47]. Most of the proteins that participate in these routes become acetylated, which indicates a potential role of acetylation in the regulation of cell metabolism.

Diacetyl intake may cause changes in protein structure, likely due to uncontrolled acetylation [8]. Altered protein structure can lead to increased ROS levels and misfolded or degraded proteins. Protein degradation may facilitate an increase in circulating amino acids and affects protein turnover [53]. Protein turnover may cause increased ammonia levels due to protein catabolism [31]. Ammonia is a toxic substance, of nitrogen metabolism, and one of the ways of eliminating excess ammonia occurs through the urea cycle. Upregulation of the urea cycle increases ureagenesis, a process that may cause changes in hepatic nitrogen homeostasis and hormonal regulation [54]. This mechanism would explain the increased metabolites related to protein biosynthesis and amino acid metabolism, both of which increase substrates of the urea cycle.

The open field test showed discrete differences between motor locomotion and social behavior expressed through anxiety/fear when comparing male and female control groups and groups treated with diacetyl. Females are less vulnerable to stress than males [55], but they are more affected by repeated stress than males [56]. Such behavioral changes may be related to changes in metabolic profile. For example, the metabolite 5-HT increased in both treated groups and is involved in the pathophysiology of anxiety disorders [57]. The alteration of 5-HT also promotes changes in behavioral expression [57]. Aside from the serotonergic system, the adrenergic and glutaminergic systems are also involved in anxiety and behavior changes.

Some metabolite alterations are found in patients or animals with hepatic or renal injury, which demonstrates the possible toxicity of diacetyl intake. However, most metabolite alterations are associated with diseases related to increase of oxidative stress and inflammation. SOD activity decreased in both treated groups while peroxynitrite increased in only female treated groups, demonstrating that there is an imbalance between prooxidants and antioxidants in diacetyltreated animals. Our results suggest that long-term intake of diacetyl is associated with oxidative stress, a relationship previously demonstrated by our group through in vitro studies. [12-15]

\section{Data Availability}

Data are available in the Supplementary Materials.

\section{Conflicts of Interest}

The authors declare no conflicts of interest regarding the publication of this paper.

\section{Acknowledgments}

The authors are grateful for funding from The São Paulo Research Foundation (FAPESP, Grant nos. 2012/02514-9, 2013/07763-0, 2018/02385-0, and 2015/14782-6), Improvement Coordination of Superior Level Personnel (CAPES) for scholarship, and the Brazilian Innovation Agency (FINEP) for support in the acquisition of LCMS/MS.

\section{Supplementary Materials}

Supplementary 1. Supplementary Material 1. Affected pathways in male groups. This material included the metabolite set for probable pathways, the total number of metabolites, expected value, $\mathrm{P}$ value, and the false discovery rate (FDR), in male groups.

Supplementary 2. Supplementary Material 2. Affected pathways in female groups. This material included the metabolite set for probable pathway, the total number of metabolites, expected value, $P$ value, and the false discovery rate (FDR), in female groups.

Supplementary 3. Supplementary Material 3. Probably disease in male groups. This material included the metabolite set for probable disease, the total number of metabolites, expected value, $\mathrm{P}$ value, and the false discovery rate (FDR), in male groups.

Supplementary 4. Supplementary Material 4: Probably disease in female groups. This material included the metabolite set for probable desease, the total number of metabolites, expected value, $P$ value, and the false discovery rate (FDR), in female groups. 


\section{References}

[1] J. D. Floros, R. Newsome, W. Fisher et al., "Feeding the world today and tomorrow: The importance of food science and technology," Comprehensive Reviews in Food Science and Food Safety, vol. 9, no. 5, pp. 572-599, 2010.

[2] T. Shibamoto and L. F. Bjeldanes, Introduction to Food Toxicology, Second. and Elselvier., Eds., 216p, Elselvier, San Diego, California, USA, 2nd edition, 2009.

[3] J. Colley, I. F. Gaunt, A. B. G. Lansdown, P. Grasso, and S. D. Gangolli, "Acute and short-term toxicity of diacetyl in rats," Food and Cosmetics Toxicology, vol. 7, no. C, pp. 571-IN21, 1969.

[4] A. F. Hubbs, W. T. Goldsmith, M. L. Kashon et al., "Respiratory toxicologic pathology of inhaled diacetyl in Sprague-Dawley rats," Toxicologic Pathology, vol. 36, no. 2, pp. 330-344, 2008.

[5] R. Kanwal, G. Kullman, K. B. Fedan, and K. Kreiss, "Occupational lung disease risk and exposure to butter-flavoring chemicals after implementation of controls at a microwave popcorn plant," Public Health Reports, vol. 126, no. 4, pp. 480494, 2011.

[6] K. Kreiss, A. Gomaa, G. Kullman, K. Fedan, E. J. Simoes, and P. L. Enright, "Clinical bronchiolitis obliterans in workers at a microwave-popcorn plant," The New England Journal of Medicine, vol. 347, no. 5, pp. 330-338, 2002.

[7] K. Kreiss, "Flavoring-related bronchiolitis obliterans," Current Opinion in Allergy and Clinical Immunology, vol. 7, no. 2, pp. 162-167, 2007.

[8] S. T. Larsen, Y. Alarie, M. Hammer, and G. D. Nielsen, "Acute airway effects of diacetyl in mice," Inhalation Toxicology, vol. 21, no. 13, pp. 1123-1128, 2009.

[9] J. W. Martyny, M. V. Van Dyke, S. Arbuckle, M. Towle, and C. S. Rose, "Diacetyl exposures in the flavor manufacturing industry," Journal of Occupational and Environmental Hygiene, vol. 5, no. 11, pp. 679-688, 2008.

[10] J. M. Mathews, S. L. Watson, R. W. Snyder, J. P. Burgess, and D. L. Morgan, "Reaction of the butter flavorant diacetyl (2,3Butanedione) with $\mathrm{N}$ - $\alpha$-acetylarginine: A model for epitope formation with pulmonary proteins in the etiology of obliterative bronchiolitis," Journal of Agricultural and Food Chemistry, vol. 58, no. 24, pp. 12761-12768, 2010.

[11] D. L. Morgan, G. P. Flake, P. J. Kirby, and S. M. Palmer, "Respiratory toxicity of diacetyl in C57BL/6 mice," Toxicological Sciences, vol. 103, pp. 169-180, 2008.

[12] A. N. L. Alves, L. D. L. Jedlicka, J. Massari, M. A. Juliano, E. J. H. Bechara, and N. A. Assunção, "Electrospray ionization mass spectrometry applied to study the radical acetylation of amino acids, peptides and proteins," Journal of the Brazilian Chemical Society, vol. 24, pp. 1983-1990, 2013.

[13] E. J. H. Bechara, F. Dutra, V. E. S. Cardoso et al., "The dual face of endogenous $\alpha$-aminoketones: Pro-oxidizing metabolic weapons," Comparative Biochemistry and Physiology Part C: Toxicology \& Pharmacology, vol. 146, no. 1-2, pp. 88-110, 2007.

[14] J. Massari, D. E. Fujiy, F. Dutra et al., "Radical acetylation of 2/-deoxyguanosine and L-histidine coupled to the reaction of diacetyl with peroxynitrite in aerated medium," Chemical Research in Toxicology, vol. 21, no. 4, pp. 879-887, 2008.

[15] J. Massari, R. Tokikawa, D. B. Medinas et al., "Generation of singlet oxygen by the glyoxal-peroxynitrite system," Journal of the American Chemical Society, vol. 133, no. 51, pp. 20761-20768, 2011.

[16] J. Massari, R. Tokikawa, L. Zanolli, M. F. M. Tavares, N. A. Assunção, and E. J. H. Bechara, "Acetyl radical production by the methylglyoxal-peroxynitrite system: A possible route for 1lysine acetylation," Chemical Research in Toxicology, vol. 23, no. 11, pp. 1762-1770, 2010.

[17] L. D. L. Jedlicka, S. B. Guterres, A. M. Balbino et al., "Increased chemical acetylation of peptides and proteins in rats after daily ingestion of diacetyl analyzed by Nano-LC-MS/MS," PeerJ, vol. 6, Article ID e4688, 2018.

[18] P. Pacher, J. S. Beckman, and L. Liaudet, "Nitric oxide and peroxynitrite in health and disease," Physiological Reviews, vol. 87, no. 1, pp. 315-424, 2007.

[19] L. Virág, É. Szabó, P. Gergely, and C. Szabó, "Peroxynitriteinduced cytotoxicity: mechanism and opportunities for intervention," Toxicology Letters, vol. 140-141, pp. 113-124, 2003.

[20] L. D. Lima Jedlicka, J. T. Jocelino Gomes Lacerda, G. Bruno Neto et al., "Alterations in proteomic and metabolomic profile in animals exposure to 2,3-butanedione: A flavoring widely used in the food industry," Free Radical Biology \& Medicine, vol. 87, p. S120, 2015.

[21] ANVISA, Regulamento Técnico Que Aprova O Uso De Aditivos Alimentares, Estabelecendo Suas Funções E Seus Limites Máximos Para A Categoria De Alimentos 19 - Sobremesas, vol. 388, Anvisa, D.O.U., Brasilia, 1 edition, 1999.

[22] FDA, CFR - Code of Federal Regulations Title 21, 2016.

[23] JECFA, "Safety evaluation of certain food additives," in WHO Food Additives Series 42, Geneva, 42 edition, 1999.

[24] E. C. Panel, "Scientific opinion on flavouring group evaluation 11, revision 3 (FGE.11Rev3): Aliphatic dialcohols, diketones, and hydroxyketones from chemical groups 8 and 10," EFSA Journal, vol. 12, EFSA Panel on Food Contact Materials, Enzymes, Flavorings and Processing Aids, no. 11, p. 60, 2014.

[25] F. K. Marcondes, F. J. Bianchi, and A. P. Tanno, "Determination of the estrous cycle phases of rats: some helpful considerations," Brazilian Journal of Biology, vol. 62, pp. 609-614, 2002.

[26] M. Mesfin, K. Asres, and W. Shibeshi, "Evaluation of anxiolytic activity of the essential oil of the aerial part of Foeniculum vulgare Miller in mice," BMC Complementary and Alternative Medicine, vol. 14, no. 1, p. 310, 2014.

[27] D. S. Egilman and J. H. Schilling, "Bronchiolitis obliterans and consumer exposure to butter-flavored microwave popcorn: A case series," International Journal of Occupational Medicine and Environmental Health, vol. 18, no. 1, pp. 29-42, 2012.

[28] S. R. Silbiger and J. Neugarten, "The impact of gender on the progression of chronic renal disease," American Journal of Kidney Diseases, vol. 25, no. 4, pp. 515-533, 1995.

[29] J. Dairou, J.-M. Dupret, and F. Rodrigues-Lima, "Impairment of the activity of the xenobiotic-metabolizing enzymes arylamine $\mathrm{N}$-acetyltransferases 1 and 2 (NAT1/NAT2) by peroxynitrite in mouse skeletal muscle cells," FEBS Letters, vol. 579, no. 21, pp. 4719-4723, 2005.

[30] L. Guoa, M. V. Milburna, J. A. Ryalsa et al., "Plasma metabolomic profiles enhance precision medicine for volunteers of normal health," Proceedings of the National Acadamy of Sciences of the United States of America, vol. 112, no. 35, pp. E4901-E4910, 2015.

[31] S. N. Goonewardena, L. E. Prevette, and A. A. Desai, "Metabolomics and atherosclerosis," Current Atherosclerosis Reports, vol. 12, no. 4, pp. 267-272, 2010.

[32] M. Cascante, L. G. Boros, B. Comin-Anduix, P. De Atauri, J. J. Centelles, and P. W.-N. Lee, "Metabolic control analysis in drug discovery and disease," Nature Biotechnology, vol. 20, no. 3, pp. 243-249, 2002. 
[33] V. Müller, A. Szabó, O. Viklicky et al., "Sex hormones and gender-related differences: their influence on chronic renal allograft rejection," Kidney International, vol. 55, no. 5, pp. 20112020, 1999.

[34] Y. Puttabyatappa, J. N. Stallone, A. Ergul et al., "Peroxynitrite mediates testosterone-induced vasodilation of microvascular resistance vessels," The Journal of Pharmacology and Experimental Therapeutics, vol. 345, no. 1, pp. 7-14, 2013.

[35] C. Ober, D. A. Loisel, and Y. Gilad, "Sex-specific genetic architecture of human disease," Nature Reviews Genetics, vol. 9, no. 12, pp. 911-922, 2008.

[36] M. Kanehisa and S. Goto, "KEGG: kyoto encyclopedia of genes and genomes," Nucleic Acids Research, vol. 28, no. 1, pp. 27-30, 2000 .

[37] M. Kanehisa, M. Furumichi, M. Tanabe, Y. Sato, and K. Morishima, "KEGG: new perspectives on genomes, pathways, diseases and drugs," Nucleic Acids Research, vol. 45, no. 1, pp. D353-D361, 2017.

[38] J. Tower, "Mitochondrial maintenance failure in aging and role of sexual dimorphism," Archives of Biochemistry and Biophysics, vol. 576, article no. 6820, pp. 17-31, 2015.

[39] K. K. Joshi, T. L. Matlack, and C. Rongo, "Dopamine signaling promotes the xenobiotic stress response and protein homeostasis," EMBO Journal, vol. 35, no. 17, pp. 1885-1901, 2016.

[40] R. J. Deberardinis and C. B. Thompson, "Cellular metabolism and disease: What do metabolic outliers teach us?" Cell, vol. 148, no. 6, pp. 1132-1144, 2012.

[41] S. P. Putri, Y. Nakayama, F. Matsuda et al., "Current metabolomics: practical applications," Journal of Bioscience and Bioengineering, vol. 115, no. 6, pp. 579-589, 2013.

[42] R. Ramautar, R. Berger, J. van der Greef, and T. Hankemeier, "Human metabolomics: Strategies to understand biology," Current Opinion in Chemical Biology, vol. 17, no. 5, pp. 841-846, 2013.

[43] S. J. Alonso, M. A. Castellano, D. Afonso, and M. Rodriguez, "Sex differences in behavioral despair: Relationships between behavioral despair and open field activity," Physiology \& Behavior, vol. 49, no. 1, pp. 69-72, 1991.

[44] M. R. Kruk, K. G. C. Westphal, A. M. M. Van Erp et al., "The hypothalamus: cross-roads of endocrine and behavioural regulation in grooming and aggression," Neuroscience \& Biobehavioral Reviews, vol. 23, no. 2, pp. 163-177, 1998.

[45] H. L. Steenbergen, R. P. W. Heinsbroek, F. Van Haaren, and N. E. Van de Poll, "Sex-dependent effects of inescapable shock administration on behavior and subsequent escape performance in rats," Physiology \& Behavior, vol. 45, no. 4, pp. 781-787, 1989.

[46] G. A. Kennett, F. Chaouloff, M. Marcou, and G. Curzon, "Female rats are more vulnerable than males in an animal model of depression: the possible role of serotonin," Brain Research, vol. 382, no. 2, pp. 416-421, 1986.

[47] S. Zhao, W. Xu, W. Jiang et al., "Regulation of cellular metabolism by protein lysine acetylation," Science, vol. 327, no. 5968, pp. 1000-1004, 2010.

[48] N. Singewald, C. Schmuckermair, N. Whittle, A. Holmes, and K. J. Ressler, "Pharmacology of cognitive enhancers for exposurebased therapy of fear, anxiety and trauma-related disorders," Pharmacology \& Therapeutics, vol. 149, pp. 150-190, 2015.

[49] D. A. Ryan, R. M. Miller, K. Lee et al., "Sex, age, and hunger regulate behavioral prioritization through dynamic modulation of chemoreceptor expression," Current Biology, vol. 24, no. 21, pp. 2509-2517, 2014.
[50] R. Radi, "Peroxynitrite, a stealthy biological oxidant," The Journal of Biological Chemistry, vol. 288, no. 37, pp. 2646426472, 2013.

[51] C. Michiels, M. Raes, O. Toussaint, and J. Remacle, "Importance of se-glutathione peroxidase, catalase, and $\mathrm{Cu} / \mathrm{Zn}-\mathrm{SOD}$ for cell survival against oxidative stress," Free Radical Biology \& Medicine, vol. 17, no. 3, pp. 235-248, 1994.

[52] M. A. Barbacanne, J. Rami, J. B. Michel et al., "Estradiol increases rat aorta endothelium-derived relaxing factor (EDRF) activity without changes in endothelial NO synthase gene expression: Possible role of decreased endothelium-derived superoxide anion production," Cardiovascular Research, vol. 41, no. 3, pp. 672-681, 1999.

[53] S. Bourgoin-Voillard, A. Goron, M. Seve, and C. Moinard, "Regulation of the proteome by amino acids," Proteomics, vol. 16, no. 5, pp. 831-846, 2016.

[54] G. E. Shambaugh, "Urea biosynthesis I. The urea cycle and relationships to the citric acid cycle," American Journal of Clinical Nutrition, vol. 30, no. 12, pp. 2083-2087, 1977.

[55] H. Dadomo, L. Gioiosa, J. Cigalotti, G. Ceresini, S. Parmigiani, and P. Palanza, "What is stressful for females? Differential effects of unpredictable environmental or social stress in CD1 female mice," Hormones and Behavior, vol. 98, pp. 22-32, 2018.

[56] A. Szeitz and S. M. Bandiera, "Analysis and measurement of serotonin," Biomedical Chromatography, vol. 32, no. 1, p. e4135, 2018.

[57] N. G. Simon, A. Cologer-Clifford, S.-F. Lu, S. E. McKenna, and $\mathrm{S}$. Hu, "Testosterone and its metabolites modulate $5 \mathrm{HT}(1 \mathrm{~A})$ and $5 \mathrm{HT}(1 \mathrm{~B})$ agonist effects on intermale aggression," Neuroscience « Biobehavioral Reviews, vol. 23, no. 2, pp. 325-336, 1998. 


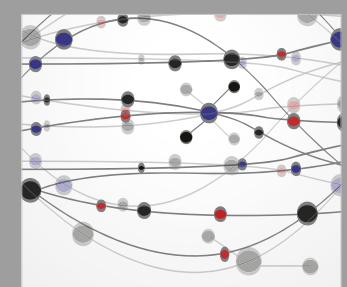

The Scientific World Journal
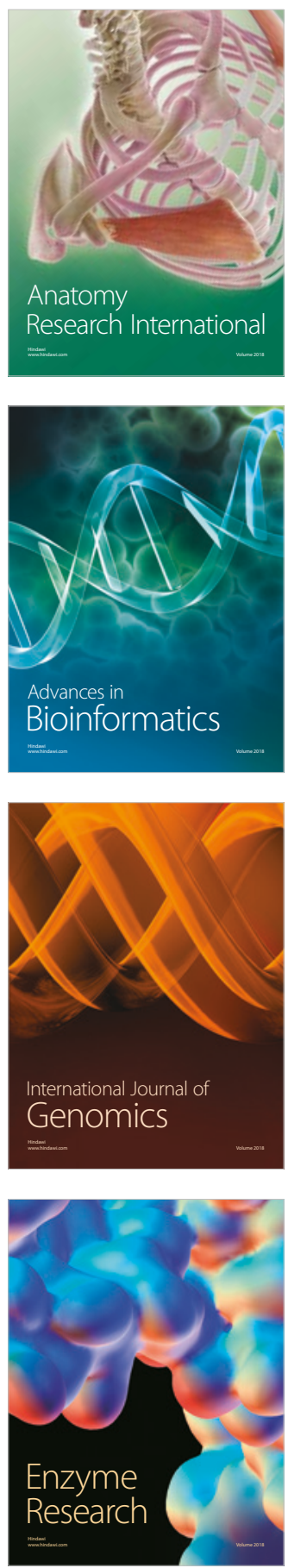
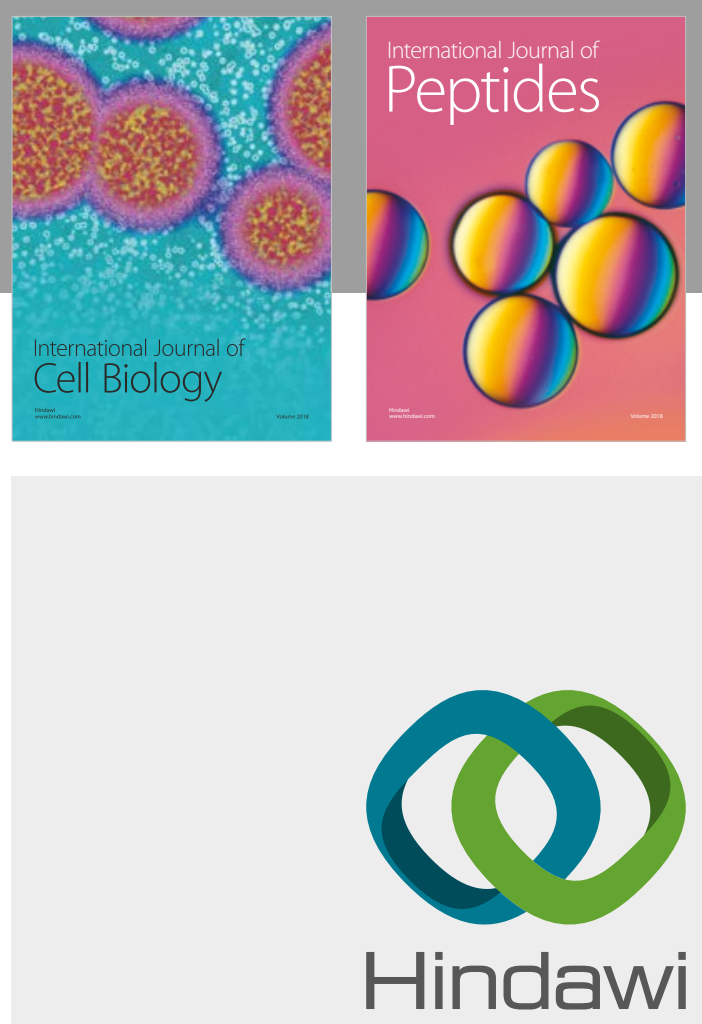

Submit your manuscripts at

www.hindawi.com
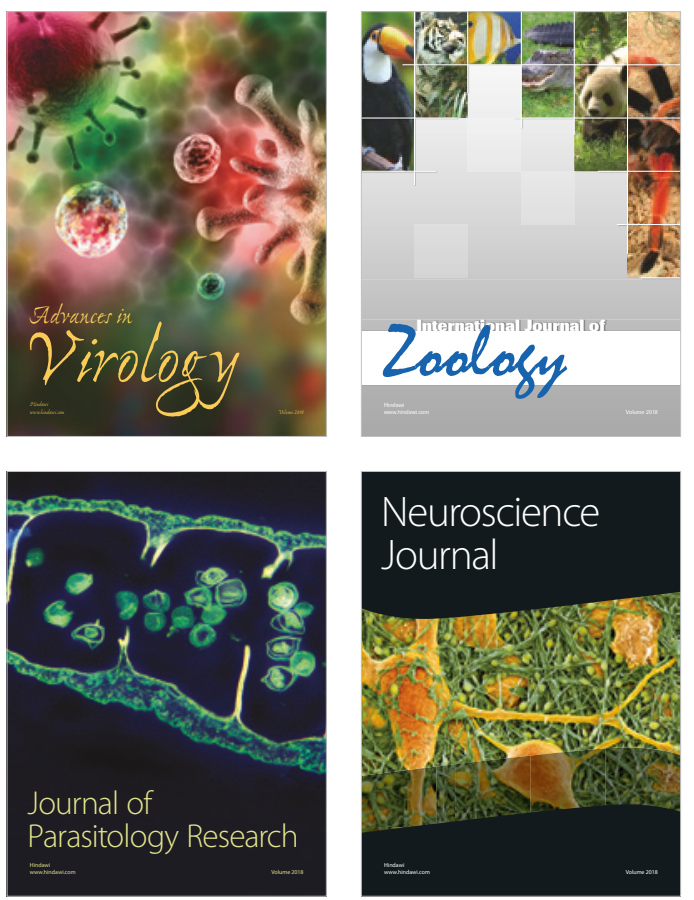
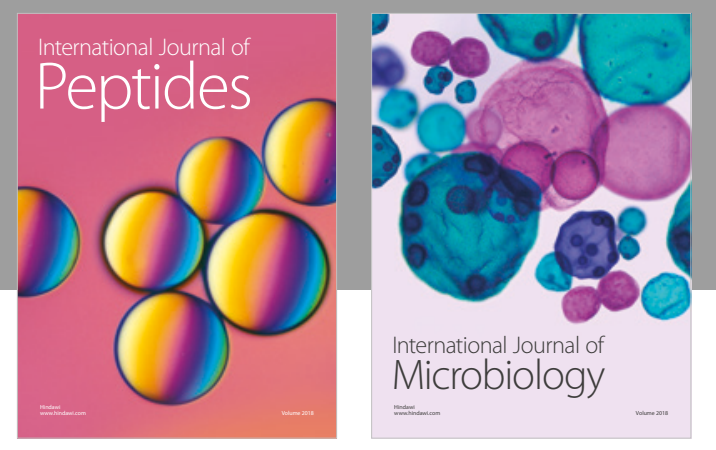

nternational Journal of Microbiology
Journal of
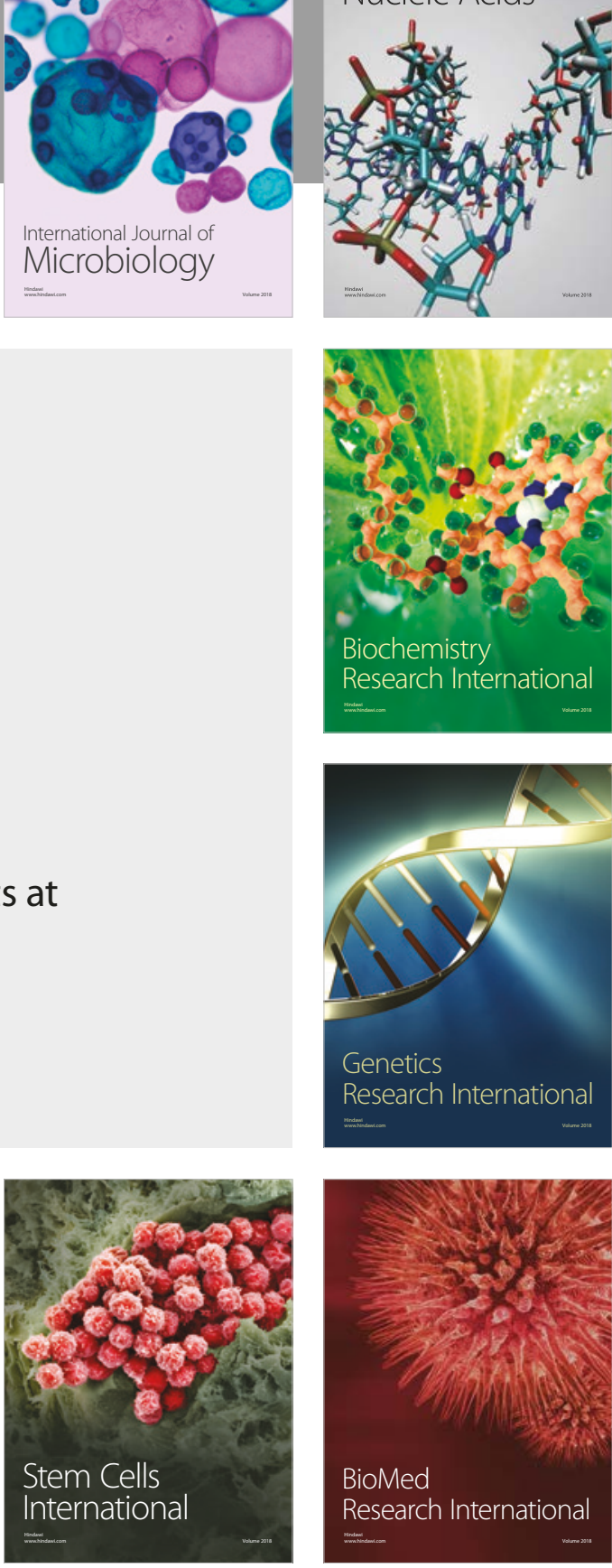
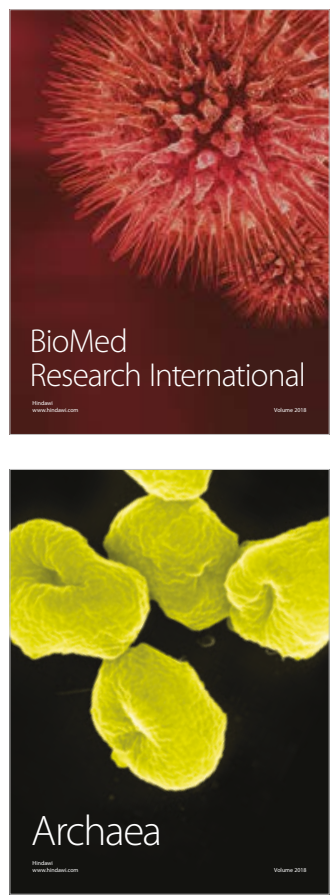